\title{
Activation of Independent Work of Future Teachers by Means of Information and Communication Technologies
}

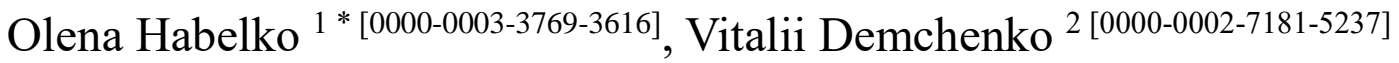 \\ ${ }^{1}$ Central Ukrainian State Pedagogical University named after V. Vynnychenko, Kropyvnytskyi, Ukraine \\ ${ }^{2}$ Central Ukrainian Institute Interregional Academy of Personnel Management, Kropyvnytskyi, Ukraine \\ *lena_gabelko@i.ua
}

\begin{abstract}
The effectiveness of higher education depends on many conditions and means. Continuous and comprehensive acquisition of theoretical knowledge and practical skills is facilitated by the use of modern information and communication technologies during all years of study in a higher education institution. Due to the penetration of new information technologies in the field of education, it has become possible to qualitatively change the content, methods, tools and organizational forms of education. The article reveals ways to intensify the independent work of future teachers by means of information and communication technologies. After analyzing the data, it was found that students in the control and experimental groups have significant differences on such scales as: awareness, decision-making, planning and communication; there is also a positive trend on mnemonic, volitional and mental scales. According to the study, it is possible to say that future teachers of the experimental group are more knowledgeable and confident in choosing their profession, they more rationally and adequately assess the situation and more thoughtfully plan their future than students in the control group. Our study allows us to draw conclusions about the need for teachers in all disciplines to implement practice-oriented content, use active methods and technologies and abandon traditional teaching methods in the absence of practical significance of the content of educational material. It is necessary to use a rating assessment of students' work in the classroom; emotional form of presentation of the material; installation on the practical significance of the subject being studied; formation of professional competencies in students; creating situations of young people's awareness of the need for vocational education to succeed in life; to actualize persistence, independence, activity, initiative at performance of educational tasks.
\end{abstract}

Keywords: independent work, professional training, future teachers, information and communication technologies.

\section{INTRODUCTION}

At this stage of development of school and education in Ukraine, it is important to find such ways to improve the intellectual potential of young people that best meet the problems of today. In our opinion, one of such ways is the widespread use of information technology in the educational process as a means of intellectual education and personal development. The issue of digitization of education in Ukraine today is quite popular and widely discussed in society, in the media and even in political circles [1].

Due to the penetration of new information technologies in the field of education, it has become possible to change qualitatively the content, methods, tools and organizational forms of education. Considering information technology as a tool of human activity, it is impossible not to recognize their positive impact on the development of intellectual, creative potential of modern youth, the formation of operational and logical thinking and cognitive independence.

The use of ICT allows educational institutions to increase their competence and fundamentally change their teaching and learning environment. Therefore, their development and implementation have become the dominant direction of numerous investments [2]. 
In our opinion, cognitive independence is an indicator that not only grows in the process of intensive and systematic educational and cognitive activities, but also has a significant impact on the success of mastering the latter and achieving high performance in learning and future professional activities [3].

\section{RESEARCH METHODOLOGY}

The methodological basis is the leading theories, pedagogical ideas and principles of science, complexity, accessibility, integrity, explaining important aspects of the problem, as well as a set of general theoretical (analysis, synthesis, comparison and generalization of scientific literature on philosophy, psychology and pedagogy, theoretical model building; synthesis of empirical material, classification, deduction, induction, modeling) and empirical (observation, questionnaire, pedagogical experiment; methods of mathematical statistics - to process the results of experimental work) research methods.

\section{DISCUSSION OF ISSUES}

Cognitive independence is a complex concept that has long attracted the attention of many researchers. Studies of the problem of development of cognitive independence are aimed at developing theoretical foundations and finding specific ways to form cognitive independence in the educational process of secondary school. In this respect, the works of I. Ya. Lerner, G. I. Shchukina, and others are of great interest. The content of cognitive independence in the scientific literature is revealed in different ways. For example, L.P Buieva, S.T Zyriakov, J.K. Uliedov highlight the socio-value aspect of this personal quality, which determines the independent position of a man. Independence, as an independent position, they refer to the spiritual and practical education, which ensures independence from external conditions, life circumstances.

K.K. Platonov, K.O. Abulkhanova-Slavska, I.A. Dzhydarian and others explore the coordination and functional aspect of cognitive independence, which reflects the possibility of various manifestations of personality as independent in cognition, communication and other activities.

Common in the approaches of these researchers is the general conclusion that the development of individual human functions, properties and personality traits is ultimately subject to the development of the whole - the individual, and "significantly depends on the objective content in which it is formed" [4, p. 416].

Particularly important for the study of the essence of an independent personality are psychological concepts of personality structure, which are marked by signs of systemic approach to their construction. O.M. Lieontiev,
B.F. Lomov, A.V. Petrovskyi and others consider cognitive independence as a defining property and quality of personality.

The content of cognitive independence was studied on the basis of general pedagogical positions. Thus, V.I. Andrieiev, V.N. Maksimova, V.S. Ilin, N.O Polovnikov, G.I. Schukina consider cognitive independence as an integral personal formation. In its structure, they highlight the human condition and the relationship that is organically linked to the activity. The main components of cognitive independence are revealed through the properties and qualities of personality.

Methods of teaching students in higher education should be characterized by a shift in attention to independent work, creating conditions that would stimulate active activity and independent mastery of knowledge. As a means, it is advisable to replace the traditional teaching methodology with technological. It is known that information and communication technologies have significant potential in the organization of the educational process [5, p. 139].

Interest in cognitive independence is explained primarily by the fact that "it is one of the most important psychological conditions for successful acquisition of knowledge, skills and abilities" [6, p. 166].

In our opinion, the structural model of cognitive independence presented by T.I. Shamova deserves special attention. Concretizing the content of this personal indicator, she proceeds from the fact that personality qualities (intellectual, emotional and volitional) are socially conditioned, individually expressed, are not innate, but are formed in active, pedagogically and expediently organized activities [7].

In this regard, she distinguishes three most important components of cognitive independence: motivational, content-operational and volitional. All these components are interdependent and interrelated, but each has its own meaning and performs certain functions (Figure 1).

\section{RESULTS OF THE RESEARCH}

The effectiveness of higher education depends on many conditions and means. Among them, the organization of the educational process and the choice of such teaching methods are of great importance, which positively affect not only the volume and depth of students' knowledge, but also the development of their ability to work independently and creatively. Properly organized independent work of the student is one of the conditions necessary for effective educational work of students and the formation of their readiness for selfimprovement. 


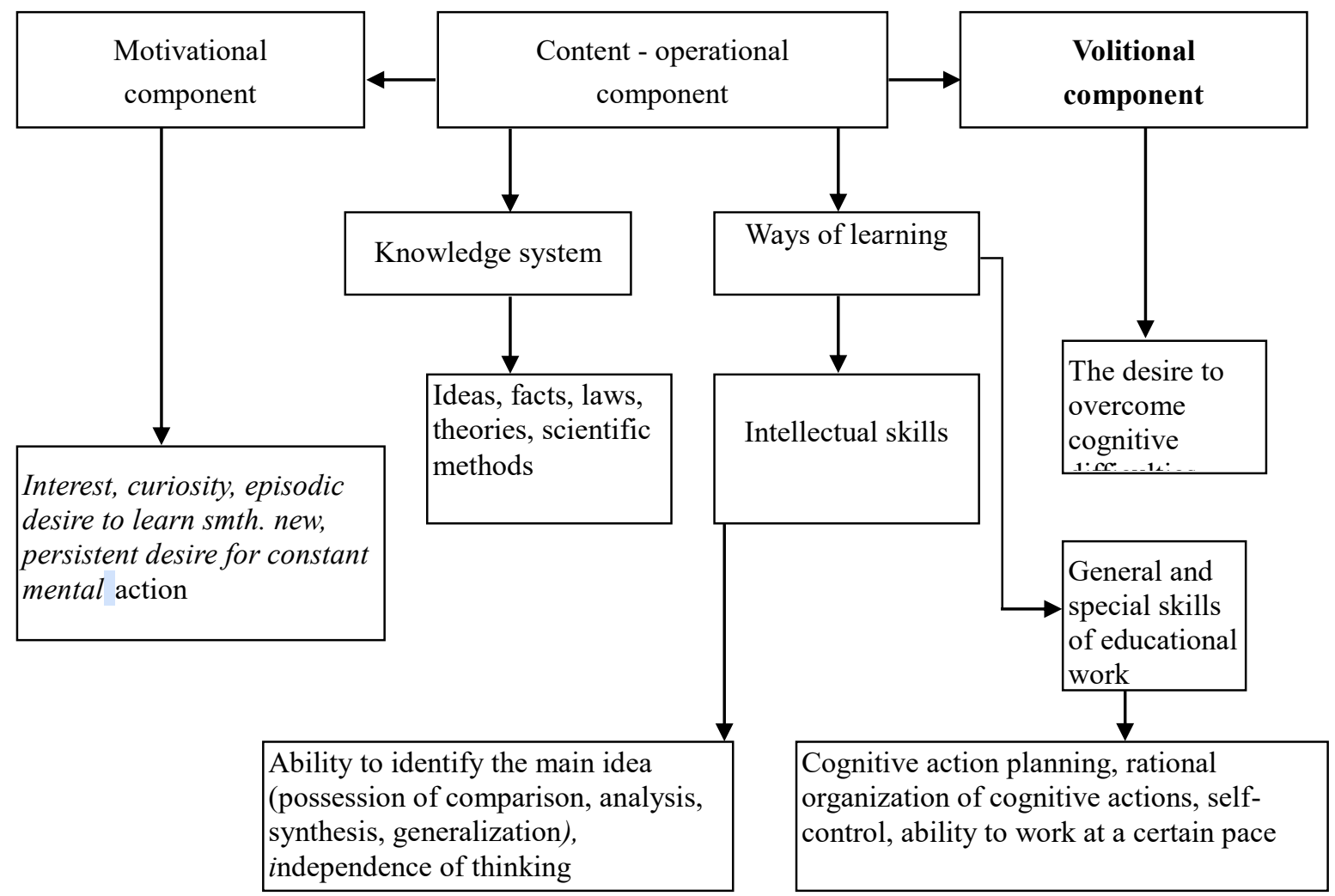

Figure 1 Structural model of cognitive independence (According to T.I. Shamova)

Continuous and comprehensive acquisition of theoretical knowledge and practical skills is facilitated by the use of modern information and communication technologies during all years of study in a higher education institution. However, it should be remembered that new technologies are introduced constantly, and also very quickly, almost immediately become obsolete as soon as they appeared [8].

The most significant changes in the development of the studied phenomenon are demonstrated by the method "Methods of diagnosing students' learning motivation" (A.A. Rean and V.O. Yakunin).

The statement was focused on identifying the level of development of educational and professional motivation in students of Volodymyr Vynnychenko Central Ukrainian State Pedagogical University.

To identify the dynamics of the development of educational and professional motivation in students when comparing the initial and final level of motivation of students at the ascertaining and control stages, the same method was used.

We found that between students of the control, experimental groups there are no significant differences in the level of development of educational, and professional motivation, they are approximately at the same level (low).
When processing the test results, the average indicator for each scale of diagnostic methods was calculated (Table 1).

Analyzing the results of the study of students' learning motivation, we obtained the following data: in first place, students had communicative motives. The motives of prestige were in the second place, and then came professional motives. In fourth place were social, educational and cognitive indicators of motives. Special attention should be paid to the students who came to the faculty primarily with motives of avoidance, motives of creative self-realization.

Then there was an open survey of students, where the following question was asked: "What is the reason for the high or low level of interest in learning"? The results of the answers show that the reasons that cause high or low interest in the discipline are the content of the material, which they study, methods of work and the personality of the teacher (Table 2).

The participants explained that in disciplines in which they have a high level of interest, the teacher implements practice-oriented content, uses active methods and technologies, and in disciplines with a low level of interest mainly traditional reproductive teaching methods are used, there is no practical significance of the content of educational material. 
Table 1. The results of the study of motivation by the method of diagnosis of student motivation (A.O. Rean and V.O. Yakunin)

\begin{tabular}{|c|c|c|}
\hline Motives & Control group (total score) & $\begin{array}{c}\text { Experimental group } \\
\text { (total score) }\end{array}$ \\
\hline Communicative & 35 & 30 \\
\hline Motives of avoidance & 5 & 8 \\
\hline Motives of prestige & 20 & 20 \\
\hline Professional & 15 & 15 \\
\hline Motives of creative self-realization & 5 & 7 \\
\hline Educational and cognitive motives & 10 & 12 \\
\hline Social & 10 & 8 \\
\hline
\end{tabular}

Table 2. Reasons for high or low level of interest in student learning

\begin{tabular}{|l|c|c|}
\hline Reasons for interest in learning & Control group & Experimental group \\
\hline Content of the studied material & $40 \%$ & $36 \%$ \\
\hline Methods of work & $36 \%$ & $32 \%$ \\
\hline Personality of the teacher & $24 \%$ & $32 \%$ \\
\hline
\end{tabular}

Thus, analyzing the presented data, we can conclude that the level of motivation to study in the control and experimental groups is conditionally at the same level, with a low interest in learning from students.

Our study allows us to draw the following conclusions. It is necessary for all disciplines to introduce practice-oriented content to teachers, to use active methods and technologies, abandon traditional teaching methods in the absence of practical significance of the content of educational material. Use a rating assessment of students' work in classes; emotional form of presentation of the material; installation on the practical significance of the studied subject; formation of professional competencies in students; creating situations of young people's awareness of the need for vocational education to succeed in life; to actualize persistence, independence, activity, initiative at performance of educational tasks.

In order to intensify the cognitive activity of students, organizing and conducting practical and theoretical classes, as well as to organize independent work of students, the emphasis was on creating developments and manuals of practice-oriented, activity nature.

With the help of information and communication technologies, diagnostic tools and methodological materials from academic disciplines and professional modules were created. Modern visualization tools and the Internet have also been used to organize and conduct classes. It is appropriate to include video viewing, computer multimedia and completing tasks, projects in the educational environment. Interaction with their content is important for students to acquire new knowledge, skills and abilities that change their perceptions and prospects [9]. Another thing to keep in mind is that new technologies are constantly being introduced, and very quickly, they become obsolete as soon as they appear [10].

According to the results of "Methods of diagnosing students' learning motivation" (A.A. Rean and V.O. Yakunin), experimental and control groups were compared before and after testing. When processing the test results, the average for each scale of the questionnaire was calculated (Table 3).

Table 3. The results of the study of learning motivation

\begin{tabular}{|l|c|c|}
\hline \multicolumn{1}{|c|}{ Motives } & Control group & Experimental group \\
\hline Communicative & 35 & 32 \\
\hline Motives of avoidance & 5 & 2 \\
\hline Motives of prestige & 15 & 23 \\
\hline Professional & 17 & 5 \\
\hline Motives of creative self-realization & 7 & 14 \\
\hline Educational and cognitive motives & 13 & 8 \\
\hline Social & 7 & 23 \\
\hline
\end{tabular}


Changes occurred in both the control and experimental groups, but in the experimental group, the indicators of motives increased more clearly. In the first place, students have communicative motives. In second place in both groups were professional motives, but with a gap of $6 \%$ with an advantage in the experimental group. Then came the motives of prestige in both groups. The table shows the changes in the experimental group - an increase in the level of professional motives, educational and cognitive, which indicates a positive trend in the development of educational and professional motivation in students.

Analyzing the presented data, we can conclude that the implementation of this pedagogical condition has increased the level of motivation of students.

To identify the degree of professional readiness, we used the method of A.P. Cherniavska (Table 4).

Table 4. Indicators of professional readiness according to the method of A.P. Cherniavska

\begin{tabular}{|l|c|c|c|c|}
\hline \multirow{2}{*}{ Indicators } & \multicolumn{2}{|c|}{ Control group } & \multicolumn{2}{c|}{ Experimental group } \\
\cline { 2 - 5 } & unformed, \% & formed, \% & unformed, \% & formed, \% \\
\hline Autonomy & 41 & 59 & 16 & 84 \\
\hline Awareness & 51 & 49 & 27 & 73 \\
\hline Decision making & 27 & 73 & 19 & 81 \\
\hline Planning & 43 & 57 & 24 & 73 \\
\hline Emotional attitude & 76 & 24 & 27 & 76 \\
\hline
\end{tabular}

The method of forming the studied phenomenon of students of the experimental group by means of hypertext, multimedia technologies and web-quest was implemented in lectures, practical, optional classes and in extracurricular time.

In general, studying the impact of these tools, we have found that their use contributes to: the activation of cognitive activity, the formation of the desire for the completion of cognitive activity. For example, in the situation of choosing between completing an unfinished problem in extracurricular activities and receiving an answer without completion, the number of students who chose the first option compared to the initial data increased by $31 \%$. In comparison with the control group in the experimental, there is a steady trend of transition from chaotic cognitive actions to the preparation of an appropriate action plan. In particular, the number of students in the experimental group increased (by 47.3\%), who successfully completed creative work related to the construction of schedules, drawing up diagrams, developing models. Creating a situation of success with a web quest affects the growth of a positive emotional background. One of the important indicators of this is the spread of active expression of cognitive interest of students in their free time. Thus, the analysis of this aspect of the problem showed that in the control group only $31.7 \%$ of students include cognitive classes in their free time, in the experimental group their share is $78.8 \%$.

The organization of educational and cognitive activities with the use of hypertext and multimedia, according to the experiment, contributed to the development of students' independence.
During the experiment, it was determined that the use of these tools has a positive effect on the quality of knowledge, in particular on their volume and strength in the experimental group (on average by $35 \%$ ); increases interest in the process of cognition, promotes the formation of positive, stable and conscious motivation to learn (approximately 39.7\%); positively influences the development of logical thinking (establishing causal relationships - by 44.4\%), analysis, synthesis, abstraction, generalization (on average by $40.3 \%$, etc.).

After processing the mathematical data obtained from the results of the study of the control and experimental groups, using the nonparametric Mann-Whitney test for independent samples, the following results were obtained.

Significant differences were found on the following scales:

- awareness $(U=153,5000, p=0,002037)$ : the ability to have a positive attitude to all types of work, the ability to distinguish between professions, as well as to identify the basic requirements of the profession to a person;

- decision-making $(U=211.5000, p=0.050041)$ : the ability to make informed, rational decisions (this is a special type of human activity aimed at choosing the way to achieve the goal, the process of choosing one or more options from many others);

- planning $(U=138.5000, p=0.000736)$ : this is a process of a coordinated activity to choose ways to achieve the goal, based on the adopted strategy or technology of the activity; the order and sequence of its execution is planned in advance; implementation of any program; 
- communicative $(U=195.5000, p=0.023206)$ : this is the process of interaction between people, during which interpersonal relationships arise, manifest and are formed. Communicativeness involves the exchange of thoughts, feelings, experiences, and therefore these skills are very important in society. Some professions have obliged to pay more attention to them, because in certain activities the main method of work is communication.

We also follow the trend on the following scales:

- mnemonic $(U=220,0000, p=0,072701)$ : these are the actions implemented in the learning process, include the following operations: orientation in the semantic structure of the material, dismemberment and grouping of semantic elements, establishing links between structural units of the text, recoding of verbal information into figurative, consolidation of the memorized material, as a whole and in parts;

- mental $(\mathrm{U}=216.5000, \mathrm{p}=0.062517)$ : this is a process that provides answers to such questions that cannot be solved by direct, sensory reflection. Thanks to thinking, a person correctly navigates in the world around him, using previously obtained generalizations in a new, specific situation.

After analyzing the obtained data, it was found that the students of the experimental group are more dominated by the ability to make more informed and considered decisions, they plan their future professional life more rationally. Students in the experimental group are more communicative than students in the control group.

\section{CONCLUSION}

Thus, the students of the control and experimental groups found significant differences on such scales as: awareness, decision-making, planning and communication; as well as a positive trend on the scales: mnemonic, volitional and mental. According to the study, it can be said that future teachers of the experimental group are more knowledgeable and confident in choosing their profession, they more rationally and adequately assess the situation and plan their future more thoughtfully than students in the control group.

\section{REFERENCES}

[1] Kulish, A. Radul, V. Haleta, Y. Filonenko, O. and Karikh, I. (2020), "The Newest Digital Technologies in Education and the Prospects of Their Implementation in Ukraine", Propósitos y Representaciones, no. 8.

[2] Qi B., Liu L. and Wang Ch. (2009), "E-learning Tools to Improve Students' Learning Experience: a case study", Int. J. Modern Education and Computer Science, vol. 1, pp. 1-9.

[3] Demchenko, V. V. (2015), Problema samovdoskonalennia osobystosti [Problem of selfperfection of personality], Academic Commentaries, Series: Pedagogical Sciences, no. 135 , pp. $96-99$.

[4] Rubinshteyn, S. L. (1973), Problemyi obschey psihologii [Problems of general psychology], Moskva, Pedagogics, 423 p.

[5] Haleta, Y. Habelko, O. and Dombrovan, T. (2018), "Development of professional maturity of future foreign language teachers by means of informational technologies", Science and Education, no 4, pp. 137-143.

[6] Kovalyov, A.K. (1963), Ocherki pedagogiki [Essays of pedagogics], L: publishing house of the Leningrad university, $312 \mathrm{p}$.

[7] Shamova, T. I. (1982), Aktivizatsiya ucheniya shkolnikov [Activation of studies of schoolchildren], Moskva, Pedagogics, 209 p.

[8] Bogdanović, M. (2012), "Growing Importance of Distance Education", Int. J. Modern Education and Computer Science, vol. 4, no. 3, pp. 35-41.

[9] Dip Nandi, Margaret Hamilton and James Harland (2015), "What Factors Impact Student - Content Interaction in Fully Online Courses", I.J. Modern Education and Computer Science, vol. 7.

[10] Bogdanović, M. (2012), “Growing Importance of Distance Education”, Int. J. Modern Education and Computer Science, vol. 4, no. 3, pp. 35-41. 